\title{
Relationship of Opening CSF Pressure and Visual Field Defect in Idiopathic Intracranial Hypertension
}

\author{
Sepideh Paybast, Farhad Assarzadegan, Behnam Safarpoor Lima, Mohsen Koosha*
}

Department of Neurology, Imam-Hossein Hospital, Shahid-Beheshti University of Medical Science, Tehran, Iran

\begin{abstract}
Background: Idiopathic intracranial hypertension (IIH) is an increased intracranial pressure with normal cerebrospinal fluid (CSF) characteristic in the absence of identifiable causes. The most important complication of this disorder is visual impairment. So far, no comprehensive study has been done on the relationship between the opening CSF pressure and visual field defect in IIH.

Methods: In this study, 35 patients with increased intracranial pressure who fulfilled modified Dandy's criteria underwent ophthalmologic examination and lumbar puncture. The opening CSF pressure was categorized into mild (25-30), moderate (30-40) and severe $(>40)$. The degree of visual field defect was reported both quantitatively and qualitatively. Eventually, the statistical relationship was established among these variables.

Results: The mean opening CSF pressure was $33.71 \mathrm{CmH} 20$. Twelve patients had minor CSF pressure, whereas in 14 and 9 patients the CSF pressure was respectively moderate and severe. There was not statistically significant relationship between the visual field defect and CSF pressure. The most common patterns of visual field involvement were enlarged blind spot and peripheral restriction. Conclusion: The most important morbidity in IIH is visual impairment. According to the findings, the visual field impairment is not pertinent to CSF pressure. In other words, neither high CSF pressure predicts intense visual defect, nor low CSF pressure indicates minimal visual impairment. Keywords: Idiopathic intracranial hypertension (IIH); Perimetry; Visual field; CSF pressure
\end{abstract}

\author{
*Correspondence to \\ Mohsen Koosha, MD, \\ Department of Neurology, \\ Imam-Hossein Hospital, \\ Shahid-Beheshti University of \\ Medical Science, Tehran, Iran. \\ Email: \\ mohsenkoosha63@gmail.com
}

Published online 19 June 2018

Citation: Paybast S, Assarzadegan F, Safarpoor Lima B, Koosha M. Relationship of opening CSF pressure and visual field defect in idiopathic intracranial hypertension. Int Clin Neurosci J. 2018;5(2):51-54. doi:10.15171/icnj.2018.10.

\section{Introduction}

Idiopathic intracranial hypertension (IIH) is a challenging disorder of intracranial hypertension in the absence of an intracranial mass, hydrocephalus, or other identifiable cause. The incidence is approximately $0.9 / 100.000$ /year rising to $13 / 100.000$ /year in overweight women between 20 and 44 years of age. Less frequently, it is seen in children and overweight men. ${ }^{1-5}$ Due to increasing prevalence of the obesity over the last years, IIH has been also on the rise. This increase is widely seen in our country, even though there still has not been painstaking information and research over the issue.

The symptoms usually progress in a few weeks to months, though fulminant cases have also been reported. IIH has a variable course ranging from a short benign self-limiting syndrome to more aggressive syndromes that proceed to blindness in a short period of time. ${ }^{5-7}$ The characteristic features of IIH include headache, visual loss, which can be irreversible if not treated promptly. ${ }^{8,9}$ Visual loss can occur anytime along the course of the disease but is often insidious as central vision is spared until late in the course of the illness. Some degrees of visual impairment are detected in up to $90 \%$ of patients by perimetry at the time of diagnosis, however only about one third complain from the vision loss. ${ }^{6,10,11}$ As long as severe and prolonged papilledema causes retinal breakdown or macular impairment, the visual acuity will be preserved. ${ }^{6,12-14}$

According to significant role of vision system concerned to environment and possibility of irreversible complication if not treated and subsequent burden on society and health system, the early diagnosis and proper treatment is in paramount of importance.

Until now, little research has been conducted on relationship of cerebrospinal fluid (CSF) pressure and visual field defect and the results are controversial. In the study of Baheti et al there was not a dramatic difference between CSF pressure in patients with either normal or subtle visual impairment or severe visual impairment. ${ }^{5}$ In contrast, Saindane et al in their study revealed that, in patients with severe visual impairment, the CSF pressure was higher whether in the form of reduced visual acuity 
or visual field defect. ${ }^{15}$ Accordingly, the purpose of this study was to evaluate the relationship of CSF pressure and the degree of visual field defect in patients with IIH.

\section{Methods}

This study was conducted descriptively as well as analytically in Imam Hossein hospital, Tehran in 20142017.

\section{Study Procedure}

Thirty five patients of any age and sex with increased intracranial pressure who fulfilled modified Dandy's criteria underwent brain MRI, ophthalmologic examination consisting of visual acuity, papilledema grading, ocular movement evaluation and perimety and lumbar puncture. The degree of visual field defect was reported quantitatively on the basis of the number complete black squares from all the 54 squares in 4 quadrants according to pattern deviation and was presented qualitatively on the Table 1.

The opening CSF pressure had been measured by lumbar puncture and manometry and subsequently 25-30 cc CSF was evaluated for glucose, protein concentration and WBC count. The CSF pressure classification was based on El-Saadany et al study. ${ }^{16}$ The pressure was categorized into mild (25-30), moderate (30-40), and severe $(>40)$.

After data collection, the statistical analysis was performed by using SPSS v22.0. Normal data distribution was performed by Kolmogorov-Smirnov test. For the comparison of the quantitative variables independent two-sample $t$ test and for the qualitative variables, chisquare test was performed. Significant $P$ value was considered less than 0.05 .

\section{Results}

Thirty-five patients were enrolled in the study. The mean age was 32 years old. The results showed that brain MRI findings of the patients was normal in 11 cases $(31.4 \%)$, abnormal in 23 cases $(65.7 \%)$ and non-specific in only one patient (2.9\%). Additionally, the mean CSF pressure was $33.7 \pm 8.97$. It was categorized into three groups as mild in 12 cases $(34.4 \%)$, moderate in 14 cases $(40 \%)$ and severe in 9 cases $(25.7 \%)$. The results are shown on Figure 1.

The mean age in the group with mild CSF pressure was lower and with moderate CSF pressure was higher $(P=0.011)$ (Table 2). It should be noted that there was not a statistical relationship between neither weight nor body mass index (BMI) with CSF pressure $(P=0.14$ and $P=0.21)$.

Among the patients, 6 cases had sixth nerve palsy which was more frequent in the group with higher CSF pressure $(44.4 \%)$. It was seen in $7.1 \%$ of patients with moderate CSF pressure and $8.3 \%$ of mild CSF pressure $(P<0.04)$.

The reduced visual acuity was seen in 6 cases in the right eye, and 7 cases in the left eye. In 4 cases, both eyes were involved and in 25 cases the visual acuity was intact.

Most patients had grade 1 papilledema (48.5\%). The papilledema grading was respectively $25.7 \%$ grade 2 , $17.4 \%$ grade 3 and $8.57 \%$ grade 4 . All the patients with mild CSP pressure had grade 1 papilledema. Among the 14 patients with moderate CSF pressure, 5 cases (35.7\%) had grade 1 papilledema and 9 cases (64.3\%) had grade 2 papilledema. Among the patients with severe CSF pressure, $66.7 \%$ had grade 2 and 3 papilledema, additionally $33.3 \%$ had grade 4 papilledema. Based on the results, there was a considerable correlation between CSF

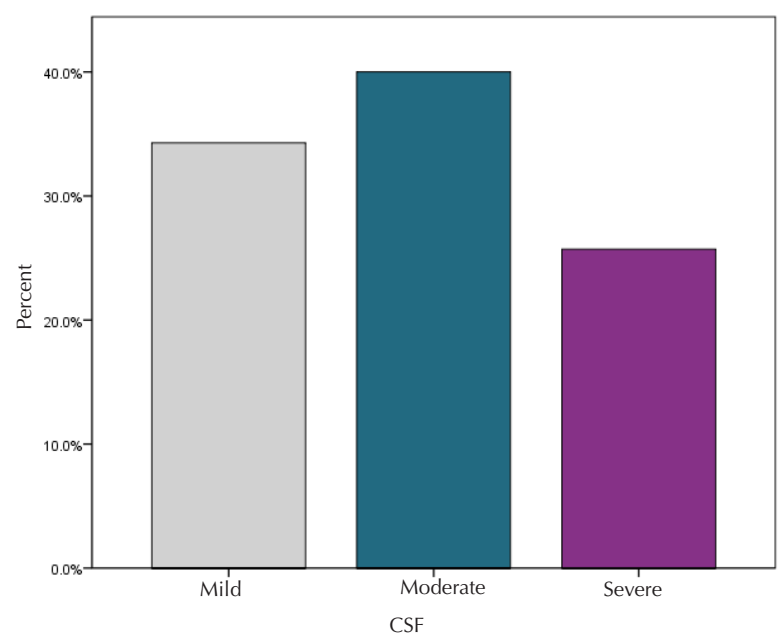

Figure 1. Description of Patients in the Term of CSF Pressure.

Table 1. Description of the Pattern of Visual Field Defect

\begin{tabular}{ll}
\hline Blind Spot Enlargement & \\
\hline $\begin{array}{ll}\text { Peripheral Restriction } \\
\text { Scotoma }\end{array}$ & Less than a quadrant \\
& Inferior nasal \\
& Superior nasal \\
& Inferior temporal \\
& Superior temporal \\
& Complete or partial of 2 quadrant: \\
& Inferior hemifield, superior hemifield, Hemitemporal, Heminasal \\
& Three quadrant (non-localized) \\
& Four quadrant (diffuse) \\
\hline
\end{tabular}


pressure and papilledema grading $(P<0.001)$. The results are shown in Tables 3 and 4 .

The visual field defect is quantitatively described based on the number complete black squares from all the 54 squares in four quadrants and are presented on the Table 5. The results did not show a meaningful relationship between the CSF pressure and the amount of the involved squares $(P=0.036)$.

\section{Discussion}

Inadequate research has been done on the relationship of CSF pressure and visual field defect. In Baheti et al study, of the total 43 patients, visual impairment was observed in 80 eyes $(93 \%)$ at presentation and it was moderate to severe in $14 \%$ showing later poorer prognosis. The mean CSF opening pressure at presentation did not differ significantly in those with visual impairment compared to those with normal vision. Over 56 months follow-up, 34 patients (79\%) improved, 4 (9.3\%) relapsed on followup after period of stability, and $5(11.6 \%)$ worsened which was similar to our findings. Besides the most common pattern of visual field defects were blind spot enlargement, peripheral restriction and nasal scotoma. ${ }^{5}$

In the study of Soiberman et al on 90 patients under 18 years old, the results showed the CSF pressure was between $20-25$ in $10 \%, 25-40$ in $48 \%$ and more than 40 in $42 \%$. Furthermore, the CSF pressure was not a predictive factor of ultimate prognosis or possibility of relapse which the same as our results. ${ }^{17}$

In contrast, in Saindane et al study, the 46 patients were categorized into three groups without vision loss, mild to moderate and severe visual impairment. The results

Table 2. Description and Comparison the Age of Patients According to the CSF Pressure

\begin{tabular}{llll}
\hline CSF & Number & Age $($ Mean \pm SD) & $P$ Value \\
\hline Mild & 12 & $26.75 \pm 4.29$ & \\
Moderate & 14 & $38.86 \pm 12.87$ & 0.011 \\
Severe & 9 & $28.33 \pm 10.10$ & \\
\hline
\end{tabular}

Table 3. Description of the Visual Field Defect Pattern (\%)

\begin{tabular}{lll}
\hline Pattern & $\begin{array}{l}\text { Right Eye } \\
\text { No. }(\%)\end{array}$ & $\begin{array}{l}\text { Left Eye } \\
\text { No. }(\%)\end{array}$ \\
\hline Normal & $3(8.6)$ & $4(11.4)$ \\
Blind Spot & $13(37.1)$ & $9(25.7)$ \\
Peripheral restriction & $3(8.6)$ & $3(8.6)$ \\
$\begin{array}{l}\text { Scotoma in less than a quadrant } \\
\text { Scotoma in more than a quadrant }\end{array}$ & $0(0.0)$ & $2(5.7)$ \\
$\begin{array}{l}\text { Blind spot and peripheral restriction } \\
\text { Blind spot and scotoma in less than a }\end{array}$ & $6(0.0)$ & $1(2.9)$ \\
$\begin{array}{l}\text { quadrant } \\
\text { Peripheral restriction and scotoma in less } \\
\text { than a quadrant }\end{array}$ & $1(2.9)$ & $8(22.9)$ \\
$\begin{array}{l}\text { Blind spot and peripheral restriction and } \\
\text { scotoma in less than a quadrant }\end{array}$ & $3(8.6)$ & $2(5.7)$ \\
\hline
\end{tabular}

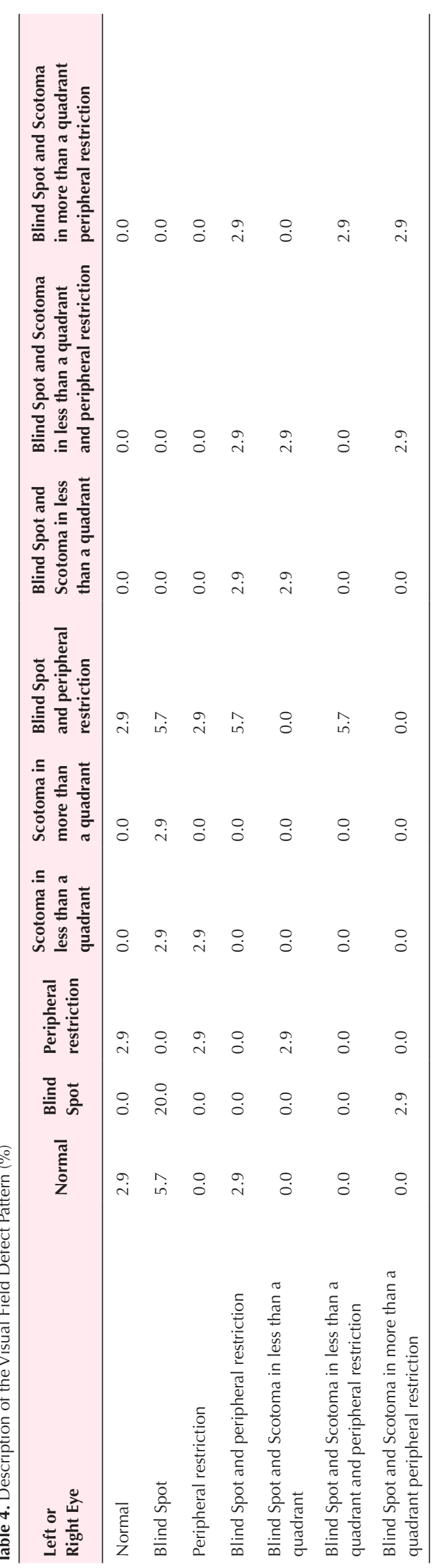


Table 5. The Relationship Between CSF Pressure and Visual Field Changes

\begin{tabular}{|c|c|c|c|c|c|c|c|c|}
\hline \multirow{3}{*}{$\begin{array}{l}\text { Visual } \\
\text { Field }\end{array}$} & \multicolumn{6}{|c|}{ CSF Pressure } & \multirow{3}{*}{ OR $(95 \% \mathrm{Cl})$} & \multirow{3}{*}{$P$ Value } \\
\hline & \multicolumn{2}{|c|}{ Mild $(n=12)$} & \multicolumn{2}{|c|}{ Moderate $(n=14)$} & \multicolumn{2}{|c|}{ Severe $(n=9)$} & & \\
\hline & Mean \pm SD & $\begin{array}{l}\text { Median (min- } \\
\text { max) }\end{array}$ & Mean \pm SD & $\begin{array}{l}\text { Median (min- } \\
\text { max) }\end{array}$ & Mean \pm SD & $\begin{array}{l}\text { Median (min- } \\
\text { max) }\end{array}$ & & \\
\hline Right & $14.17 \pm 11.85$ & $14(0-33)$ & $11.07 \pm 10.97$ & $8(0-42)$ & $20 \pm 17.83$ & $20(0-54)$ & $1.02(0.98-1.07)$ & 0.367 \\
\hline Left & $12.67 \pm 11.88$ & $8(2-41)$ & $20.43 \pm 23.67$ & $12.50(0-67)$ & $11.33 \pm 10.71$ & $8(2-28)$ & $1.00(0.97-1.04)$ & 0.995 \\
\hline Mean & $13.42 \pm 9.89$ & $15.25(2-32.5)$ & $15.75 \pm 16.41$ & $10.25(0-47)$ & $15.67 \pm 12.75$ & $11(2-37)$ & $1.01(0.96-1.06)$ & 0.705 \\
\hline
\end{tabular}

indicated that as higher the CSF pressure, more visual impairment is seen. The mean CSF pressure in these groups was $31,31.4$ and 48 , respectively. ${ }^{15}$

In other studies, the relationship of CSF pressure and visual field defect was not exclusively evaluated.

\section{Conclusion}

In approach to $\mathrm{IIH}$, the first diagnostic and therapeutic action is lumbar puncture. On the other hand, the most important morbidity is visual impairment which could be irreversible. Based on our results, visual field impairment is independent of CSF pressure. In other words, neither high CSF pressure predicts intense visual defect, nor low CSF pressure indicates minimal visual impairment. In fact, perimetry is the best diagnostic method to evaluate the patients in follow up.

Conflict of Interest Disclosures

The authors declare that they have no conflict of interests.

Ethical Statement

This article has been accepted with ethics cod IR.sbmu.ram. Rec.1394.472.

\section{References}

1. Digre KB, Nakamoto BK, Warner JE, Langeberg WJ, Baggaley SK, Katz BJ. A comparison of idiopathic intracranial hypertension with and without papilledema. Headache. 2009;49(2):185-93. doi: 10.1111/j.1526-4610.2008.01324.x.

2. Friedman DI, Liu GT, Digre KB. Revised diagnostic criteria for the pseudotumor cerebri syndrome in adults and children. Neurology. 2013;81(13):1159-65. doi: 10.1212/ WNL.0b013e3182a55f17.

3. Durcan FJ, Corbett JJ, Wall M. The incidence of pseudotumor cerebri. Population studies in lowa and Louisiana. Arch Neurol. 1988;45(8):875-7.

4. Sorensen PS, Krogsaa B, Gjerris F. Clinical course and prognosis of pseudotumor cerebri. A prospective study of 24 patients. Acta Neurol Scand. 1988;77(2):164-72.

5. Baheti NN, Nair M, Thomas SV. Long-term visual outcome in idiopathic intracranial hypertension. Ann Indian Acad Neurol. 2011;14(1):19-22. doi: 10.4103/0972-2327.78044.

6. Eissa E, Daker L, Shaban M, Hegazy M. Lumbar puncture as a single modality for treatment of idiopathic intracranial hypertension during pregnancy. Egypt J Neurol Psychiatr Neurosurg. 2016;53(1):33-6. doi: 10.4103/11101083.176367.

7. Craig JJ, Mulholland DA, Gibson JM. Idiopathic intracranial hypertension; incidence, presenting features and outcome in Northern Ireland (1991-1995). Ulster Med J. 2001;70(1):31-5.

8. Wall M, Kupersmith MJ, Kieburtz KD, Corbett JJ, Feldon SE, Friedman DI, et al. The idiopathic intracranial hypertension treatment trial: clinical profile at baseline. JAMA Neurol. 2014;71(6):693-701. doi: 10.1001/jamaneurol.2014.133.

9. Wall M. Idiopathic intracranial hypertension (Pseudotumor cerebri). Curr Neurol Neurosci Rep. 2008;8(2):87-93. doi: 10.1007/s11910-008-0015-0.

10. Thurtell MJ, Wall M. Idiopathic intracranial hypertension (pseudotumor cerebri): recognition, treatment, and ongoing management. Curr Treat Options Neurol. 2013;15(1):1-12. doi: 10.1007/s11940-012-0207-4.

11. Thurtell MJ, Bruce BB, Newman NJ, Biousse V. An update on idiopathic intracranial hypertension. Rev Neurol Dis. 2010;7(2-3):e56-68.

12. Jensen $\mathrm{RH}$, Radojicic $\mathrm{A}$, Yri H. The diagnosis and management of idiopathic intracranial hypertension and the associated headache. Ther Adv Neurol Disord. 2016;9(4):317-26. doi: 10.1177/1756285616635987.

13. Wall M. The importance of visual field testing in idiopathic intracranial hypertension. Continuum (Minneap Minn). 2014;20(4 Neuro-ophthalmology):1067-74. doi: 10.1212/01. con.0000453302.20110.29.

14. Fisayo A, Bruce BB, Newman NJ, Biousse V. Overdiagnosis of idiopathic intracranial hypertension. Neurology. 2016;86(4):341-50. doi: 10.1212/wnl.0000000000002318.

15. Saindane AM, Bruce BB, Riggeal BD, Newman NJ, Biousse V. Association of MRI findings and visual outcome in idiopathic intracranial hypertension. AJR Am J Roentgenol. 2013;201(2):412-8. doi: 10.2214/ajr.12.9638.

16. El-Saadany WF, Farhoud A, Zidan I. Lumboperitoneal shunt for idiopathic intracranial hypertension: patients' selection and outcome. Neurosurg Rev. 2012;35(2):239-43. doi: 10.1007/s10143-011-0350-5.

17. Soiberman U, Stolovitch C, Balcer LJ, Regenbogen M, Constantini S, Kesler A. Idiopathic intracranial hypertension in children: visual outcome and risk of recurrence. Childs Nerv Syst. 2011;27(11):1913-8. doi: 10.1007/s00381-011-1470-5. 